\title{
Trabalho e Tempo: Modos de Subjetivação das Trabalhadoras Safristas das Indústrias do Fumo de Santa Cruz do Sul
}

Trabajo y Tiempo: Modos de Subjetivación de las Trabajadoras Safristas de las Industrias del Fumo de Santa Cruz Do Sul

Work and Time: Modes of Subjectivation of Safristas Workers from the Tobacco Industries of Santa Cruz Do Sul

\author{
Renata da Silveira Borstmann \\ ORCID: https://orcid.org/0000-0001-9669-3742 \\ Universidade Federal do Rio Grande do Sul - Rio Grande do Sul/Brasil
}

Karine Vanessa Perez

ORCID: https://orcid.org/0000-0003-1643-8042 Universidade de Santa Cruz do Sul - Rio Grande do Sul /Brasil

\section{Resumo}

O trabalho, por ser central na vida dos sujeitos, tem o potencial de atravessar e constituir a subjetividade dos trabalhadores. O trabalho na safra nas indústrias de fumo constitui-se como um importante meio de subsistência para uma considerável parcela de mulheres de uma cidade do interior do Rio Grande do Sul. Desse modo, este artigo se propõe a discutir a relação entre trabalho e tempo nos processos de subjetivação das trabalhadoras safristas das indústrias do fumo de Santa Cruz do Sul. Esse estudo ancorou-se nos pressupostos teóricos e metodológicos da Psicodinâmica do Trabalho, no qual foram realizados três encontros de grupos com quatro trabalhadoras safristas no Sindicato dos Trabalhadores do Fumo e da Alimentação (STIFA) e quatro entrevistas individuais. A análise dos materiais evidenciou que as participantes se subjetivam nesse trabalho temporário que se configura como um modo de trabalhar em que há uma interrupção e, ao mesmo tempo, continuidade ao longo dos anos. Foi constatado que o trabalho na safra se constitui como uma atividade essencialmente feminina, dado o elevado número de trabalhadoras mulheres nesse ramo produtivo. Essas questões denotam, portanto, o modo como as trabalhadoras se estruturam e se organizam neste contexto de trabalho, se subjetivando nesta temporalidade sazonal, seja pela falta de opções de emprego ou pela repetição durante vários anos na safra, mesmo que contrarie o desejo de um emprego efetivo.

Palavras-Chave: Trabalho de safra; Precarização do trabalho; Trabalho e gênero; Produção de subjetividade; Psicodinâmica do trabalho.

\section{Resumen}

El trabajo, por ser central en la vida de los sujetos, tiene el potencial de atravesar y constituir la subjetividad de los trabajadores. El trabajo temporal en las industrias de tabaco se constituye como un importante medio de subsistencia para una considerable proporción de mujeres de una ciudad del interior de Rio Grande do Sul. De este modo, este artículo se propone discutir la relación entre trabajo y tiempo en los procesos de subjetivación de las trabajadoras safristas de las industrias del humo de Santa Cruz del Sur. Este estudio se ancló en los presupuestos teóricos y metodológicos de la Psicodinámica del Trabajo, en el que se realizaron tres encuentros de grupos con cuatro trabajadoras safristas en el Sindicato de los Trabajadores del tabaco y, de la Alimentación (STIFA) y cuatro 
entrevistas individuales. El análisis de los materiales evidenció que las participantes se subjetivan en ese trabajo temporal que se configura como un modo de trabajar en que hay una interrupción y al mismo tiempo continuidad a lo largo de los años. Se constató que el trabajo temporal se constituye como una actividad esencialmente femenina, dado el elevado número de trabajadoras mujeres en esa rama productiva. Estas cuestiones denotan, por lo tanto, el modo en que las trabajadoras se estructuran y se organizan en este contexto de trabajo, si se subjetivan en esta temporalidad estacional, ya sea por la falta de opciones de empleo o por la repetición durante varios años en la safra, aunque contraríe el deseo de un trabajo empleo efectivo.

Palabras Clave: Trabajo de safra; Precarización del trabajo; Trabajo y género; Producción de subjetividad; Psicodinámica del trabajo.

\begin{abstract}
The work, for being central in the life of the subjects, has the potential to go through and constitute the subjectivity of the workers. The temporary work in the tobacco industry is an important mean of subsistence for a large portion of women in a country city of Rio Grande do Sul. Thus, this article proposes a discussion about the link between work and time in the subjectivation processes of the safristas workers of the tobacco industry of Santa Cruz do Sul. This study was based in the theoretical and methodological assumptions of the Psychodynamics of Work, in which three group meetings with four safrista workers at the Tobacco and Food Workers Syndicate (STIFA) and four individual interviews were made. The analysis of the material showed that the participants were subjectivated in this temporary work which is characterized as a way of working in which there is an interruption and, at the same time, continuity over the years. It was verified that the safra work constitutes itself as an essentially feminine activity given the high number of female workers in this productive field. These issues therefore denote the way the workers structure and organize themselves in this context of work, becoming subjectivated in this temporal sazonality, be it for the lack of job offers or by the repetition for several years in the safra, even if it contradicts the desire for an effective work.
\end{abstract}

Keywords: Safra work; Precarization of work; Work and gender; Subjectivity production; Psychodynamics of work.

\section{Introdução}

As recentes e profundas transformações no mundo do trabalho, baseada na forma capitalista de produzir, implicaram em grandes consequências para a vida dos trabalhadores, dentre as quais a precarização das condições de trabalho. Desta maneira, houve um aumento na flexibilização das relações de trabalho, que são manifestadas, principalmente, na instabilidade dos empregos, na informalização, nos trabalhos subcontratados, temporários e parciais, além da perda dos direitos e conquistas trabalhistas.

Todas essas mudanças têm produzido um forte impacto sob a classe trabalhadora, afetando a inserção ao mercado de trabalho, principalmente para o público feminino, visto que, historicamente, as mulheres sempre foram desvalorizadas em detrimento do trabalho masculino. O desemprego, o aumento dos postos de trabalho temporário, com jornada parcial e com menores rendimentos, ainda abrange, em maior número, o segmento feminino (Nascimento, 2014).

Situada no interior do Rio Grande do Sul, a cidade de Santa Cruz do Sul é conhecida como a "Capital do Fumo". Na cidade encontra-se o maior complexo de beneficiamento de fumo em folha, contando com a presença de grandes indústrias fumageiras. Sendo assim, grande parte do mercado de trabalho da cidade está envolvida 
na dinâmica deste ramo produtivo (Cadoná, 2015).

Durante um determinado período do ano o número de pessoas empregadas no munícipio se eleva devido à necessidade de utilização de mão de obra para a safra. A maioria dos trabalhadores safristas são do segmento feminino, as quais atuam na linha de produção da indústria. A possibilidade de trabalho nas fumageiras representa, para uma grande parcela de mulheres que possuem pouca ou nenhuma qualificação, uma oportunidade de ingressar no mercado de trabalho. Para muitas, esta é a única experiência de emprego que possuem, repetindo-se por diversos anos, seja na mesma empresa ou em várias.

Neste contexto social, muitas mulheres com baixa ou até mesmo sem nenhuma qualificação, provindas, principalmente, de bairros periféricos da cidade, tem como possibilidade de emprego o trabalho de safra nas indústrias fumageiras. Essa atividade sazonal, em muitos casos, é a única experiência profissional que essas mulheres possuem, sendo um trabalho marcado por interrupção previsível, mas repetidas ao longo dos anos. Dessa maneira, no período em que inicia a safra do fumo, as trabalhadoras se organizam e entram em estado de espera para o retorno a este trabalho nas indústrias.

Portanto, pretende-se neste artigo destacar a relevância deste estudo que busca estabelecer uma discussão sobre as relações entre trabalho e tempo nos processos de subjetivação de mulheres. A temporalidade que atravessa o trabalho de safra produz efeitos nos processos de subjetivação destas trabalhadoras. Mesmo sem manter um vínculo de continuidade durante o restante do ano neste emprego e sem ter a garantia de que serão contratadas novamente na safra seguinte, estas se constituem e se denominam como "trabalhadoras safristas".

Sendo assim, neste trabalho propõe-se a compreender a relação entre trabalho e tempo nos processos de subjetivação das trabalhadoras safristas, tendo em vista que este fazer é marcado por interrupção previsível e, ao mesmo tempo, continuidade ao longo dos anos. Além disso, discutir através de uma perspectiva de gênero, quais os impactos que as transformações contemporâneas no mundo trabalho acarretam na vida destas trabalhadoras.

\section{Precarização do trabalho e gênero}

Nas últimas décadas, o trabalho precário aparece como resultado do crescimento da globalização e a expansão do neoliberalismo, que por meio da reestruturação produtiva contribuiu para que as condições de trabalho se tornem cada vez mais flexíveis. Nesse sentido, o trabalho precário pode ser caracterizado como a ausência da proteção social e de direito, a redução da jornada de trabalho, que resultam em salários reduzidos, além de baixos níveis de qualificação (Hirata, 2002).

Por sua vez, a precarização do trabalho pode ser compreendida como um processo social constituído por uma ampliação e institucionalização da "instabilidade" e da "insegurança", ou seja, se configura como a perda dos direitos trabalhistas, colocando o estado como regulador do mercado de trabalho e das leis que regem a proteção social. Enquanto processo amplo, a situação da precariedade é evidenciada pela redução dos empregos permanentes ou estáveis nas empresas, bem como pela subcontratação de trabalhadores(as) temporários por tempo determinado, em tempo parcial ou eventuais (Guiraldelli, 2014).

Ainda que um considerável número de trabalhadores(as) tenha sido atingido pela redução dos postos de trabalho e pela precarização nas relações produtivas, alguns grupos sociais foram e são particularmente afetados em maior proporção. A construção social da divisão sexual do trabalho possibilitou que o capital se apropriasse da desigualdade existente nas relações de gênero, de modo que a precarização das condições de 
trabalho torna-se mais evidente para as mulheres (Hirata, 2002).

O desenvolvimento tecnológico e os novos métodos de gestão de produção criaram novas oportunidades de empregos para o público feminino, inclusive em postos de trabalho que antes eram ocupados, especialmente, por homens. Entretanto, essa maior inclusão das mulheres no mercado de trabalho ocorreu devido às empresas alterarem sua política de contratação, visando à redução de custos. Diante disso, a feminização no interior das indústrias implicou em uma desqualificação nos processos de trabalho, no qual as atividades passaram a ser desenvolvidas com movimentos repetitivos e em condições precárias, justificando assim, a redução dos salários (Hirata, 2002).

De acordo com Guiraldelli (2014) a atual situação das mulheres no mercado de trabalho é ainda marcada de maneira desigual se comparada à dos homens, e essa desigualdade permanece durante toda a sua trajetória. Há uma distinção nas oportunidades de qualificação profissional e ofertas de emprego entre homens e mulheres. Assim, tarefas dotadas de maior desenvolvimento tecnológico são preenchidas em grande medida pelo trabalho masculino, enquanto as disponíveis às mulheres são tarefas rotineiras que exigem movimentos repetitivos, pouco qualificados e em condições precárias (Hirata, 2002).

Outro fator que deve ser levado em conta é que com a diminuição dos postos de trabalho e o elevado número de desempregos, desencadeado pela reestruturação produtiva iniciada na década de 1990, situação em que muitas mulheres tiveram que ingressar no mercado de trabalho com o objetivo de complementar a renda familiar. Porém, essa mudança no contexto laboral e a ideia de que a remuneração feminina seria complementar a masculina fez com que as mulheres recebessem uma baixa remuneração, (Queiroz \& Aragon, 2015). Assim sendo, observa-se que a inserção feminina no mercado de trabalho ainda é vista e interpretada de maneiras diferentes, em que o trabalho do homem é considerado fundamental, enquanto o da mulher complementar.

Um dos fatores que também impede uma melhor situação da mulher no mercado de trabalho é a manutenção e a preservação do modelo de família patriarcal. A produção de subjetividade masculina e feminina são construídas social e culturalmente e determinam, na maioria das vezes, quais as os espaços a serem ocupados por homens e mulheres, além das funções a serem exercidas. Assim, o aumento do ingresso da mulher no espaço produtivo não extingue suas atividades no espaço reprodutivo. Conforme Hirata (2002) a maior inserção da mulher no mercado de trabalho não significa uma distribuição igualitária dos afazeres domésticos e o cuidado dos filhos, pois continuam dedicando uma grande parcela do tempo a estas atividades em comparação aos homens.

De acordo com Antunes (2009) a mulher, por ser responsável pela realização das tarefas de trabalho tanto dentro quanto fora de casa, torna-se duplamente explorada pelo capital. Isso acontece porque esse sistema econômico necessita do trabalho das mulheres no espaço doméstico, pois conforme Nogueira (2004, p. 225) "[...] é imprescindível para o seu processo de valorização, uma vez que seria impossível para o capital realizar seu ciclo produtivo, sem o trabalho feminino realizado na esfera reprodutiva". Sendo assim, a construção sociocultural do papel da mulher tem sido utilizada como argumento para a precarização do trabalho feminino, manifestada na contração de mulheres em trabalhos parciais e temporários, viabilizando assim, a dinâmica reprodutiva do sistema capitalista nos diferentes espaços (Hirata, 2002).

As novas configurações do trabalho decorrentes do processo de flexibilização, tem contribuído no estabelecimento de novos regimes temporais no trabalho (através da contração de trabalhos parciais ou temporários) e são as mulheres que vivem mais intensamente a tensão dessa pluralidade 
dos tempos (Hirata, 2002). Todas essas mudanças que afetam o tempo do trabalho, consequentemente afetam a subjetividade das trabalhadoras. Nesse sentido, as novas experimentações temporais acarretam em implicações nos modos de ser e viver na contemporaneidade e no mundo do trabalho.

\section{Método}

A referente pesquisa ancora-se nos pressupostos teóricos e práticos da Psicodinâmica do Trabalho (PdT), que tem como principal objetivo compreender a relação entre prazer-sofrimento no trabalho. A Psicodinâmica do Trabalho visa compreender aspectos psíquicos e subjetivos que são mobilizados através das relações e da organização do trabalho. Assim, a PdT possui um método específico que une a intervenção à pesquisa, sendo assim, baseado nos princípios da pesquisa-ação, sendo também conhecida como Clínica do Trabalho. De acordo com Dejours (2008) a Psicodinâmica enquanto clínica, se descoloca sobre um trabalho de campo que é totalmente diferente de um lugar da cura, ou seja, implica que, a fonte de inspiração é o próprio trabalho de campo, se deslocando e retornando de modo constante a ele.

A pesquisa-ação faz parte da metodologia da PdT, pois leva em consideração a não neutralidade do pesquisador. Ou seja, tem em vista as trocas realizadas entre o(a) pesquisador(a) e o(a) trabalhador(a) (Dejours, 2008). De acordo com Thiollent (1988) a pesquisa-ação pode ser considerada

[...] um tipo de pesquisa com base empírica que é concebida e realizada em estreita associação com uma ação ou com a resolução de um problema coletivo e no qual os pesquisadores e participantes representativos da situação ou do problema estão envolvidos de modo cooperativo ou participativo (p. 14).
A pesquisa foi realizada com 8 trabalhadoras safristas das indústrias do fumo de Santa Cruz do Sul. A constituição da amostra se deu a partir da disponibilização dos contatos das trabalhadoras pelo Sindicato dos Trabalhadores do Fumo e da Alimentação de Santa Cruz do Sul-RS. Os critérios utilizados para selecionar as participantes foi de que as mesmas tenham trabalhado, no mínimo, duas safras consecutivas. A escolha por este número mínimo de safra trabalhadas ocorre devido ao desejo de compreender, juntamente com as trabalhadoras safristas, a vivência deste trabalho, no qual é marcado por previsibilidade em sua interrupção e repetição

A proposta inicial desta pesquisa era a realização de encontros de grupos com as trabalhadoras safristas. Contudo, tendo em vista a dinâmica deste trabalho sazonal, não foi possível realizar apenas os encontros de grupo, devido ao pequeno número de participantes mobilizadas. Desse modo, algumas alterações foram necessárias no decorrer do andamento da pesquisa, em que foi necessário realizar algumas adaptações na metodologia. Assim, foram incluídas entrevistas individuais semiestruturadas com as trabalhadoras safristas, além daquelas realizadas coletivamente.

No total foram realizados três encontros de grupo com quatro trabalhadoras safristas. Os mesmos aconteceram na sala de reuniões do Sindicato dos Trabalhadores do Fumo e da Alimentação da cidade de Santa Cruz do Sul/RS. Como complemento a metodologia proposta inicialmente, foram realizadas quatro entrevistas semiestruturadas com as trabalhadoras as safristas. As mesmas foram agendadas previamente, de acordo com as possibilidades das participantes, sendo realizadas em um ambiente adequado que pudesse garantir a privacidade das entrevistadas. A participação na pesquisa aconteceu de forma voluntária, as quais as participantes que foram informadas, previamente, a respeito do tema e objetivos da pesquisa. 
Antes de ser realizado o projeto de pesquisa passou por avaliação do Comitê de Ética em Pesquisa da Universidade de Santa Cruz do Sul que forneceu parecer favorável para a sua realização (CAAE: 62831816.4.0000.5343).

\section{Análise e discussão dos resultados}

As trabalhadoras participantes da pesquisa possuem idade entre 37 a 79 anos, caracterizando uma média de 52,12 anos. As escolaridades das participantes variaram entre 3 que possuem ensino fundamental incompleto, 3 ensino fundamental completo e 2 ensino médio completo. Todas as participantes são casadas, exceto uma, que é viúva. Todas as participantes possuem filhos, variando entre 2 a 6 filhos.

O tempo de trabalho de safra variou entre 4 a 40 anos, obtendo uma média de 17,25 anos. Em relação as empresas, houve 4 diferentes indústrias fumageiras em que as participantes trabalham atualmente. Apenas duas participantes não estavam trabalhando na safra do fumo no momento da realização da pesquisa. Das oito trabalhadoras que participaram da pesquisa, apenas uma exerce outro tipo de trabalho durante a safra e a entressafra - atuando como diarista - sendo que as demais trabalham apenas durante o período da safra.

O material da pesquisa constituiu-se, principalmente, dos comentários verbais proferidos pelas trabalhadoras durantes os encontros de grupos e as entrevistas. Além disso utilizou-se o diário de campo para registro de observações realizadas no campo. Buscou-se extrair da fala das trabalhadoras os aspectos em comuns e relevantes da realidade do trabalho de safra. Foram priorizadas as vivências subjetivas, pois para a $\operatorname{PdT} \mathrm{o}$ objetivo não é desvendar os fatos do trabalho e sim abordar aquilo que é experiência pelo sujeito nas situações de trabalho. Assim, o comentário pode ser considerado a matériaprima da subjetividade dos(as) trabalhadores(as) (Dejours, 1992).
Para melhor compressão dos resultados encontrados no campo - principalmente do que foi observado nos encontros de grupos e entrevistas individuais $-\mathrm{a}$ análise dos comentários verbais emitidos pelas participantes foram divididos em eixostemáticos, sendo que neste artigo serão apresentados os seguintes: organização do trabalho na safra e sua relação com o tempo; oportunidade profissional; modificação nas contratações temporárias e impactos na subjetividade; empoderamento feminino e feminização do trabalho na safra do fumo.

\section{Organização do trabalho na safra e sua relação com o tempo}

O trabalho na safra nas empresas fumageiras configura-se como um trabalho temporário, que em um período do ano exige uma mão de obra maior para determinado seguimento da organização de acordo com a demanda, sendo um típico modelo Just in time (Guiraldelli, 2014). De acordo com Castel (2003) o trabalho de safra se configura com diferentes modos de organização do trabalho que se unem visando de aumentar a produtividade, o controle do tempo, a fragmentação das atividades e a utilização de dispositivos disciplinares.

A lógica deste trabalho sazonal perpassa a questão do tempo. Em média o tempo de trabalho da safra no fumo dura de cinco a seis meses para os trabalhadores(as) que se encontram na área de produção da empresa. Dessa forma, pode-se perceber que, trabalho e tempo, entrelaçam o novo cenário contemporâneo através das mudanças da reestruturação produtiva. As novas tecnologias vão incidir sobre o tempo de trabalho e com isso, afetar a subjetividade e modos de vida dos(as) trabalhadores(as) (Grisci, 1999). Essa vivência, para algumas participantes da pesquisa, é experimentada de forma transitória, conforme apontado nos seguintes comentários verbais.

Na minha opinião, eu acho que a safra deveria ser mais tempo, né. Que nem eu falei, seria bem melhor. Seria 
bem melhor não só esses meses e deu, né.

[...] é daí tu tem que se adaptar. Porque como eu disse, quando tu começa a começar a se organizar e a gostar do dinheiro, vai lá e encerra, sabe. Aí tu tem que te organizar. Depende, antes dava 8 meses de safra, então tu ficava pouco tempo em casa até, né.

Aí termina a safra, a gente fica triste. Porque terminou. Então a gente vai para casa. Aí eu assim, por mim, assim, porque eu não tenho trabalho depois dessa, eu tenho que esperar até o próximo ano. Aí o meu marido, ainda bem que eu tenho ele, porque ele que me sustenta, que dá as coisas que eu preciso. Então ele só trabalha sozinho, durante esse período até [...] $E$ até ele nem quer que eu vá para outro lugar.

Há, portanto, um desejo de continuidade neste trabalho, visto que quando há uma adaptação na rotina e uma organização da questão financeira, ocorre uma ruptura neste trabalho e neste modo de viver. O sentimento de tristeza e impotência perpassa os comentários verbais das participantes, tendo em vista que não terão outro trabalho depois de saírem da safra e se tornarão dependentes novamente do dinheiro dos companheiros. A necessidade de reorganização está presente neste fluxo do tempo, na medida em que retornarão para a um período que ficarão sem receber salário e estarão vivenciando predominantemente a rotina da casa, para após voltarem a se reorganizar para a próxima safra que acontecerá no ano seguinte.

As mudanças no mundo laboral ocasionadas através da flexibilização, implicou na adaptação a nova lógica do mercado através de novas tecnologias, novos paradigmas e novos hábitos. A fragmentação e as novas configurações de tempo e espaço, que são desencadeadas pelos novos contextos societários contemporâneos, se concretizam nos processos identitários dos(as) trabalhadores(as) visto que estes vivenciam momentos de transição e/ou interrupção (Coutinho, Krawulski \& Soares, 2007). Estas mudanças são marcadas pela questão do trabalho e do tempo, implicando em novos modos de viver e se subjetivar. Assim, na medida que a realidade se transforma, os sujeitos também são transformados (Grisci, 1999).

Do mesmo modo que as vivências trazem transformações e possíveis prejuízos psíquicos, algumas participantes consideram o fato de trabalhar por alguns meses como algo positivo, em que o período de ficar apenas em casa causa-lhes um sentimento de satisfação e descanso. Além disso, a questão da saúde também é fator que influencia neste sentimento, visto que para algumas mulheres, principalmente as mais idosas, relatam não possuir mais condições físicas de estar ativas durante todo o ano neste trabalho.

Eu acho bom. Tu fica 6 meses em casa, daí depois tu sai aqueles 6 meses, vê gente diferente, conversa.

É que eu assim, quando era mais nova, eu até preferia trabalhar assim como efetivo. Mas agora com a idade que eu tô eu não pretendia mais, para mim tá bom. E eu não tenho uma saúde lá 100\%, eu acho que eu nem aguento mais o serviço sempre, só tirando um mês de férias. E então, agora nesse tempo é uma vantagem.

O tempo que eles dão 5, 6 meses [...] Claro, aperta, né, em casa um pouco. Mas para minha saúde, porque eu quase não tenho condições muito mais.

Evidenciou-se, portanto, que a vivência de trabalhar poucos meses é marcada pelo desejo de continuar neste trabalho, tendo em vista a organização da rotina e a garantia financeira. Mas, por outro lado, a atividade descrita se apresenta como uma possibilidade 
de trabalho que, de certa forma, viabiliza as trabalhadoras que não possuem condições físicas e/ou psicológicas para se manterem o ano inteiro em uma rotina penosa $\mathrm{e}$ desgastante.

\section{Modificações nas contratações temporárias e impactos na subjetividade}

Em março de 2017, foi aprovado na Câmara dos Deputados o Projeto de Lei 4. 302/1998, alterando dispositivos da Lei $\mathrm{n}^{\mathbf{0}}$ 6.019 , de 1974, que trata do trabalho temporário em empresas urbanas e dispõe sobre as relações de trabalho nas empresas de prestação de serviços a terceiros. Sendo assim, neste dia o projeto foi sancionado pela Presidência da República, tornando-se a Lei 13.429/2017. Esse projeto, enviado à Câmara dos Deputados em 1998, tratava inicialmente da ampliação do Contrato de Trabalho Temporário, porém foi modificado para regular as empresas que realizam a contratação dos(as) trabalhadores(as) temporários (DIEESE, 2017).

A principal modificação nesta lei se referente a possibilidade da ampliação do prazo do contrato, que pode ser de 180 dias, prorrogáveis por mais 90 dias. Porém, ao final desse prazo, o(a) trabalhador(a) só poderá ser contratado novamente após 90 dias. Além disso, a contratação de trabalhadores(as) temporários somente poderá ocorrer "para atender à necessidade de substituição transitória de pessoal permanente ou à demanda complementar de serviços" (art. $2^{\circ}$ da Lei 13.429/178, Brasil, 2017). Essas modificações na legislação estão presentes nas falas das participantes.

Não, não cheguei a efetivar porque eu saí para ir para a fumageira. Daí foi o ano que eu trabalhei de fevereiro a dezembro na fumageira. Geralmente é 6 meses agora, a safra...

É, que nem antes as safras eram mais longas, agora que tão ficando mais curtas.
Era muito bom antes... Agora virou lei trabalhar 6 meses.

De acordo com as trabalhadoras safristas, anteriormente a contratação no trabalho da safra do fumo era em um período relativamente maior de como é atualmente, visto que algumas passavam praticamente o ano todo neste trabalho, ficando apenas um mês fora. Conforme a nota técnica disponibilizada pelo Departamento Intersindical de Estatística e Estudos Socioeconômicos (DIEESE, 2017) neste ano, a Lei do Contrato Temporário, não garante a segurança jurídica tão almejada pelas empresas e pode levar ao aumento de conflitos dessas formas de contratação, trazendo para os(as) trabalhadores(as) maior insegurança, instabilidade e precarização das condições de trabalho. O descontentamento em relação as novas formas de contratação são manifestadas pelas trabalhadoras, no que diz respeito a redução e a imprevisibilidade quanto ao tempo de trabalho.

Cada vez fica mais difícil. Eles não favorecem [...] Não fazem nada para favorecer a gente, né, na safra.

Na minha opinião, eu acho que a safra deveria ser mais tempo, né. Que nem eu falei, seria bem melhor. Seria bem melhor não só esses meses e deu, né.

Porque daí a gente pode comprar bem mais coisa. Pode contar com aquilo ali. É certo né. Tu trabalha todo 10, 11 meses é certo, né. Fica um mês em casa... Bem melhor se fosse certo todas as safras...

O desejo do aumento do tempo de contrato torna-se um desejo preponderante entre as trabalhadoras safristas. Preferem trabalhar durante onze meses e folgar um, sendo que este um mês de "férias" não seria remunerado. As mesmas parecem não ser dar conta do quanto este trabalho é precarizado e do quanto teriam mais acessos a direitos e benefícios caso fosse um trabalho efetivo com 
carteira assinada, ou seja, trabalhando o mesmo tempo e folgando durante um mês com férias remuneradas.

A aprovação da Lei 13.429/2017, combinada a outras medidas propostas no Projeto de Lei 6.787/2016, afeta drasticamente as condições de vida dos(as) trabalhadores(as). Além disso, alterará a estrutura do mercado de trabalho, aprofundando a heterogeneidade, a rotatividade e as desigualdades já existentes. Em consequência, serão ampliadas as desigualdades sociais no país, contribuindo para a "massificação do bico", já que o prazo do contrato de trabalho temporário vai de 90 para 240 dias. Há um aumento na precarização do trabalho, pois as empresas poderão manter os(as) trabalhadores(as) durante o período que necessitarem, podendo demiti-los sem justa casa, sem nenhum direito garantido (DIEESE, 2017).

As transformações decorrentes das formas da organização do trabalho de safra, bem como as mudanças ocasionadas nas contratações estão marcadas diretamente comentários verbais das trabalhadoras e nas entrelinhas de suas falas, demarcando $o$ descontentamento e a insegurança perante $o$ campo de trabalho. Todas essas modificações causam diversos impactos sobre 0 funcionamento psíquico, causando os mais diversos efeitos sobre a saúde mental dos(as) trabalhadores(as) (Flach, Grisci, Silva, \& Manfredini, 2009). Há uma produção de sentimento de incerteza perante este campo de trabalho, conforme apontado nos comentários verbais de algumas participantes.

[...] Tá bem diferente. A gente ia lá, queria trabalhar e já saia de lá encaminhada. Hoje não. Hoje tá assim: será que vão me chamar? Então tu fica nessa dúvida...

$E$ É não tem previsão... Pois é, tu vê hoje é diferente.

É, o garantido é o contrato que a gente assina, né, que é agora é até vencer. Aí depois vai renovar ou não vai renovar. É instável, né.

De acordo com Tavares (2010) a dinâmica atual do cenário contemporâneo vem gerando uma grande instabilidade, pois ao mesmo tempo que se conquista algo, logo pode-se estar sujeito a perder, sem nenhuma garantia de que tais aquisições sejam eternas e duradouras. Assim, o sentimento de incerteza se faz permanente, principalmente no âmbito do trabalho de safra, podendo ocasionar um profundo mal-estar e sofrimento psíquico. As modificações na própria forma de organização do trabalho, também acarretam desconforto e incerteza quanto possíveis contratações, pois a cada momento encontram dificuldades quanto ao processo de reingresso na safra.

[...] às 11 horas nós fumo na firma. Porque a minha filha disse "mãe tão colocando gente para trabalhar [...]". Fumo lá às 11 horas e já saímos com tudo pronto para trabalhar. Hoje já tem que ir 3, 4 vezes na firma.

Hoje tu tem que ir lá e pegar uma senha e mandar um currículo, é bem diferente né...

Primeiro tu vai lá para fazer um teste [...] E depois fui para levar a carteira e fazer exame médico. Sempre tem que ir mais vezes... Mas antes aqui na Empresa 1 e na Empresa 2, tinha que ir 3 ou 4 vezes... Um vez era para assinar, outra vez para fazer o exame médico, outra vez para ir lá pegar a roupa.

Outro aspecto que foi evidenciado como uma questão que lhes causam sofrimento é o tempo de trabalho. As participantes da pesquisa, apresentaram como maior desvantagem, a redução do tempo de contratação na safra, manifestando o desejo de que fosse em um tempo maior ou que fosse um trabalho efetivo. Além disso, trazem a questão da preocupação quanto à aposentadoria, pois com o trabalho de safra, a 
mesma acontece mais lentamente, pois necessitam trabalhar duas safras para conseguir validar um ano de trabalho.

\section{[...] desvantagens é que não é efetivo, é só safra, né.}

Se a safra ficasse efetiva era melhor, né.

Que nem agora é só 6 meses.

Mas também no final tem a questão da tua aposentadoria [...] Porque é mais difícil, tu tem que trabalhar duas safras para dar um ano, né.

A insegurança e a incerteza perante o campo de trabalho predominam o cenário contemporâneo laboral. O trabalho na safra do fumo, conforme verbalizado pelas trabalhadoras, provoca muitas vezes estes sentimentos, provindos da instabilidade nas contratações e na própria legislação. Além disso, a redução do tempo de trabalho também é uma questão que ocasiona preocupação e sofrimento, tendo em vista que desejam uma continuidade de trabalho durante todo o ano, principalmente devido às questões financeiras e ao acesso a direitos trabalhistas, como a aposentadoria. Dessa maneira, podem ocasionar, além do prejuízo financeiro, prejuízos psicológicos como sobrecarga emocional, ansiedade, medo e estresse (Bouyer, 2010).

\section{Feminização do trabalho na safra do fumo}

O movimento pela emancipação do sexo feminino que teve seu início no século $\mathrm{XX}$, combateu algumas questões que tornavam a mulher invisível ocasionando algumas transformações no contexto social, passando a atuar para além do espaço privado, ingressando assim no mercado de trabalho (Macedo, Boava, Cappelle, \& Oliveira, 2012).

Cabe salientar, que mesmo com todas essas conquistas, a mulher ainda não possui a igualdade de gênero por completo, pois todos os acontecimentos ainda são centrados no público masculino. Assim, o avanço das mulheres no mundo do trabalho é gradual, não conseguindo romper em absoluto com o modelo patriarcal (Macedo et al., 2012). A divisão sexual do trabalho se mostra na medida que são construídas tarefas a serem desenvolvidas por homens e mulheres. Aos homens há uma associação de execução de trabalhos nobres, já às mulheres, o desempenho de trabalhos periféricos (Hirata, 2002).

Todas essas transformações e construções sócio históricas levaram a diferentes modos de subjetivação. Além disso, as relações de gênero são vividas e experienciadas de maneira distintas, em que ambos atribuem diferentes significações à sua atividade laborativa (Macedo et al., 2012).

A inserção da mulher no mercado de trabalho é marcada por impasses, segregações e discriminações, colocando-as, geralmente, em condições menos favoráveis no campo profissional. Essa realidade é evidenciada a partir das condições trabalhistas e especialmente, pela forma como as mulheres se inserem no mundo laboral. As explicações para este panorama são um conjunto de fatores, tendo origem tanto no campo econômico, quanto a fatores socioculturais e institucionais: a diferença e a identidade feminina (biológica e social), o trabalho produtivo e reprodutivo, bem como a relação entre capitalismo e patriarcalismo, evidenciando a divisão sexual do trabalho (D'alonso, 2008).

Conforme já mencionado, este trabalho torna-se para muitas mulheres a única experiência possível dentro do mercado de trabalho formal. Essa realidade também é expressa através dos comentários verbais das participantes quando afirmam que há um número maior de mulheres atuando neste segmento, em comparação aos homens.

Ali é mais mulher. Muitas mulher. Eu acho que homem tem só uns 20. 
[...] Tem um setor que tu olha assim, é só mulher. O setor da destalal. Isso é umas 200, 300 mulheres, só assim num lugar.

\section{Mais mulheres. Sempre mais mulheres.}

No que concerne ao próprio processo de produção do tabaco, a pesquisa realizada por Redin (2015), aponta que as mulheres participam de praticamente todas as etapas, como na produção de mudas, repicagem, plantio, capina, desponte, colheita e na classificação interna do tabaco, com exceção de atividades consideradas mais pesadas, como a aração a boi para lavrar a terra, a aplicação dos agrotóxicos e o carregamento de fardos. Não obstante, as mulheres no contexto da fumicultura, atuam incisivamente na classificação das folhas, pela sua característica detalhista e por ser considerado um trabalho leve. Esta aparece também como uma própria exigência das indústrias do tabaco, tendo em vista que exigem folhas de boa qualidade. Contudo, na visão do "chefe da família" o trabalho da mulher ainda não tem tanta relevância no impacto final da produção, por isso o considera como um trabalho marginal.

\section{Estas características femininas} apontadas no processo da fumicultura, também aparecem no ingresso das mulheres no trabalho de safra, que acontece principalmente na linha de produção da indústria. Geralmente, realizam tarefas que exigem menor ou nenhuma qualificação, repetitivas e que necessitam de habilidade manual e delicadeza (manuseio das folhas do fumo). Já os homens ficam com a função de chefias e funções que exigem um esforço físico maior. De acordo com os comentários verbais das participantes, há uma naturalização desta prática, que para elas é uma questão óbvia que este trabalho deve ser realizado por mulheres.

1Destala é o setor onde se tira o talo da folha para em seguida ser posta em molhos e transformada no rolo. (informação obtida através das falas das participantes).
Eu acho que porque a maioria o serviço é para mulher, né. Porque o piker $^{2}$ é mulher.

[...] Mas geralmente é mulher que tá destalando. Que nem no piker, tu não via um homem no piker. O homem era mais do serviço braçal, né. Tipo para ir lá e adicionar um fumo, ou carregar uma caixa, montar uma caixa, né.

Porque o serviço que tem é mais para mulher. É para a destala. O homem, $o$ que que o homem faz, o homem pega o talo, tem o serviço mais pesado. E a mulher não...

"Trabalho de mulher" é a forma como as participantes da pesquisa denominaram o as atividades na safra no fumo. De acordo com Fiorin, Oliveira e Dias (2014) a diferença entre "trabalho de homem" e "trabalho de mulher" ainda estabelece um valor, sendo depreciado, muitas vezes, aquilo que é associado ao feminino. Há uma relação de que o homem é visto como poderoso e forte, já a mulher é concebida como frágil e dócil. Essas concepções corroboram para que a entrada no mundo do laboral para as mulheres ocorra de maneira desigual.

No setor produtivo, geralmente, as profissões que exigem força física e trabalhos pesados, em ambiente sujos ou insalubres, geralmente são associados a estereótipos masculinos, pois necessitam de coragem e força. Já o trabalho feminino é associado a algo que seja leve e fácil, que exija paciência e minuciosidade, caracterizando assim, a divisão sexual do trabalho (Fiorin, Oliveira, \& Dias, 2014).

Em relação as posições de lideranças no trabalho de safra, estes são ocupados majoritariamente por homens, segundo as falas das trabalhadoras safristas. Criou-se uma

2É a etapa que são retiradas as folhas de fumo que não são adequadas para o processamento final (informação obtida através das falas das participantes). 
cultura de que o homem possui um poder de liderança e de persuasão maior, sendo que elas consideram que apenas estes conseguirão gerenciar um número grande de mulheres presentes no trabalho de safra. Além disso, as oportunidades de crescimento são evidenciadas na maioria das vezes para os homens em relação às mulheres.

Sim, já são comentários. Que mulher com mulher não vai dar certo, né. Que as mulheres não vão respeitar as mulheres como encarregadas. $E$ os homens já põem mais respeito.

\section{[...] porque que nem para comandar uma turma de 179 mulher, não é fácil, né.}

Mas para lidar com um bando de mulher...Só homem mesmo. $O$ pior setor da empresa é a destala.

Percebe-se, portanto, a existência da divisão sexual no trabalho de safra, em que há uma tendência de colocar homens em cargos de maior qualificação e responsabilidade. A questão referente ao gênero no âmbito do trabalho implica em uma relação que, na maioria das vezes, o masculino é mais valorizado, o que consequentemente, produzem uma distribuição de oportunidades desiguais de poder, autoridade e prestígio entre as pessoas, conforme o seu sexo. Essas relações são construídas constantemente ao longo da história, em que a ideologia dominante reforça e reproduz a subalternidade da mulher, passando a se apoiar nela para a sobrevivência de suas estruturas hierárquicas, patriarcais e conservadoras (Macêdo \& Macedo, 2004).

Entretanto, há uma pequena movimentação entre as mulheres safristas, de questionar essas posições estabelecidas dentro das empresas, bem como a cultura que se estabeleceu dentro do contexto social do trabalho. Algumas concebem estas situações como uma reprodução machista, pois percebem a necessidade de haverem oportunidades de crescimento igualitária para todos.

Eu acho que é machismo da parte deles, né. Mas é que eles não querem dar chance para a mulher, isso todo mundo já viu... Eles sempre dão uma puxadinha por ser mulher....

Contudo, evidenciou-se que as relações de gênero que colocam, muitas vezes, as mulheres em uma posição inferior em relação ao homem, se apresentam dentro do contexto do trabalho da safra do fumo. Há uma cultura instaurada de que os trabalhos que exigem uma maior cuidado e paciência são destinados à mulher e os trabalhos que exigem uma força maior, para os homens. Além disso, a concepção de que os homens devem estar em posições de liderança para que os processos de trabalho aconteçam adequadamente, também estão presentes nos discursos produzidos pelas trabalhadoras. Porém, pode-se perceber que, lentamente, está havendo uma modificação nesta forma de pensamento, em que há uma reflexão e problematização dos discursos e práticas sexistas.

\section{Oportunidade profissional e empoderamento feminino}

O trabalho na safra do fumo, representa para a população mais pobre, uma oportunidade de ingressar - mesmo que temporariamente - no mercado de trabalho. Assim, para muitas trabalhadoras safristas este trabalho se configura como única oportunidade profissional, tendo em vista o fato da baixa escolaridade e qualificação, já que as tarefas desempenhadas na safra não possuem uma exigência de ensino formal. A dificuldade de conseguir um trabalho efetivo corrobora para a entrada neste trabalho sazonal.

\footnotetext{
É que não tem como trabalhar efetivo, né... A maioria quer estudo, né. E aí a gente não teve estudo, criado para fora... Aí a gente tinha, ia até o segundo, terceiro, até o primário todo...
} 
Eu por causa de falta de estudo. Antigamente a gente morava na colônia, só tinha até $4^{a}$ série. Não tinha como ir. Depois que eu tava aqui, com 18 anos que eu comecei a ir de novo no colégio. Me formei na $8^{a}$, né. E depois [...] não consegui emprego. Era só a safra do fumo mesmo. Era muito difícil. Ou era doméstica ou diarista, né, ou só safra.

Não, eu tentei quando eu era mais nova (trabalho efetivo). Tentei mas não consegui. Não foi possível.

A faixa etária também é um fator determinante para o ingresso na safra, visto que uma das participantes relatou dificuldade em reingressar de modo efetivo no mercado de trabalho, devido a sua idade "avançada", conforme mencionado por um contratante e relatado por ela. De acordo com Goulart Junior, Mergulhão, Canêo, Najm e Lunardelli (2009), estamos vivendo um momento em que os mais velhos são rejeitados por não serem mais considerados produtivos. O aumento da idade é acompanhado pela desvalorização, tendo em vista que se vive a exaltação da mercadoria sobre o homem e se tem a força de trabalho em detrimento da valorização humana.

A dificuldade é agora depois que meu marido faleceu. Aí eu não encontrei mais serviço. Aí eles me perguntaram a idade, né. Aí eu tava com 54, daí eles me responderam "ah, com 54 já não tem mais quase serviço para a senhora". Em três agências que eu fui. [...] Daí não me deram, não tinha como eu trabalhar, daí. Daí eu fiquei em casa e esperei a safra.

O trabalho na safra do fumo se apresenta também como uma possibilidade de trabalho, devido muitas mulheres conseguirem se organizar e adaptar à rotina da casa e ao cuidado com os filhos, que, para muitas, isto ainda fica a cargo de suas responsabilidades.
Este trabalho torna-se possível pois na safra há a existência do terceiro turno (22 horas às 5 horas). Muitas não têm com quem deixar os filhos durante o dia e, com a dificuldade de encontrar vagas em creches, optam por deixar os filhos aos cuidados do companheiro na madrugada para que possam trabalhar.

[...] Aí depois eu casei, com 24. Daí comecei na safra. Daí não tinha onde deixar o nenê, não tinha creche aquela época. Aí até que conseguisse, né. E daí eu fui para a safra de noite, e daí de dia eu fico em casa.

Trabalhei muitos anos a noite. Eu trabalhava só a noite e daí eu e meu marido, nós trocava. Porque não tinha creche também. [...] Aí nós tinha que fazer assim.

O trabalho profissional e familiar ainda está organizado de acordo com uma estruturada que acontece através de papéis de gênero estabelecidos socialmente. Sendo assim, é esperado que as mulheres estejam mais próximas ao ambiente familiar e doméstico do que os homens, oferecendo um tempo maior de cuidado (Vanalli, \& Barham, 2012). Tendo em vista esta construção social e cultural, a falta de tempo para família e as dificuldades em acompanhar o crescimento dos filhos ocasionam sentimento de perda e culpa nas mulheres trabalhadoras por não estarem presentes a maior parte do tempo em casa.

Eu mais para não deixar as crianças muito em casa atirada sozinha, para ter alguém em casa, mais presente, daí eu faço só safra. Tive já duas oportunidades de trabalhar efetivo. Mas não quis. Agora que eles estão grande, até dá para pensar um efetivo.

Só que assim, eu sinto um pouco, porque eu fico um pouco ausente dos filhos, sabe... Porque eu comecei a trabalhar cedo. Quando o meu marido me conheceu, eu 
tinha 18, 19 anos. Daí com 20 anos já a gente casou. Então, eu depois eu tive os filhos, e pouco eu pude ficar com eles, sabe? Porque a necessidade era grande, a gente pagava aluguel e tudo. Não tinha moradia, então era obrigado a levantar e trabalhar. Tinha que deixar os filhos, tinha que levar para a creche, eles eram pequenos. Tinha a guria com 3 anos e já tinha $o$ outro nenê, então tinha que carregar um no colo, era muito trabalhoso. [...]. Sabe, isso não é fácil.

O trabalho na safra do fumo se apresenta, portanto, como uma oportunidade de trabalho para muitas mulheres que não possuem características exigidas pelo mercado de trabalho efetivo. Além disso, é um trabalho que se torna possível, tendo em vista a organização familiar que ainda é estruturada com a mulher como sendo a única responsável pela manutenção da mesma. Diante dessas configurações, as trabalhadoras safristas se sentem limitadas para adentrar no mundo do trabalho, tendo em vista o sistema social que as coloca responsáveis pelos cuidados domésticos e educação dos filhos, o que as impede de buscar um trabalho efetivo, já que não dividem tais tarefas com seus companheiros.

Por muitos anos as mulheres dependiam única e exclusivamente da fonte de renda de seus companheiros. Nesse contexto, o papel da mulher esteve, por muitas vezes, associado à submissão. Contudo, na década de 1970, através das conquistas e dos avanços dos movimentos feministas relativos a inserção da mulher em espaços considerados masculinos, estas passaram adquirir recursos para se empoderarem e conseguirem lutar por uma maior autonomia (Cortez \& Souza, 2008).

A questão financeira é um dos motivos para o ingresso na safra do fumo. Algumas participantes, por não terem a possibilidade de ter um emprego fixo, tornam-se dependentes financeiramente dos maridos. Assim, a safra se torna uma saída para que possam adquirir bens que desejam tanto para elas quanto para os filhos, bem como ter a independência de fazer suas próprias escolhas.

Eu foi para ganhar o meu dinheirinho para adquirir minhas coisas e as coisas para as crianças.

$\mathrm{Na}$ época, como eu fiquei muito tempo em casa, né... Na época para ter um dinheiro. Para ser assim, para tentar ser um pouco mais independente, né. Porque até então era tudo com o marido, né. Dependia de tudo, né. Até de um desodorante [...] Porque mulher é mais vaidosa, né. Aí eu fui. Eu arrisquei, sabe. Porque os filhos eram pequenos...

[...] Fonte de renda, porque daí tu pode fazer o que tu quer, né. Tu pode fazer outra coisa. É interessante. Quem não trabalha, não tem aquele "up" pra frente.

Conforme já mencionado, o trabalho de safra mesmo que se constitui como um trabalho temporário, este permanece ao longo da vida para as trabalhadoras safristas. A questão financeira também é um dos motivos para o reingresso neste trabalho, de acordo com os comentários verbais das participantes.

O motivo é o troco, né. Ter mais um troquinho. Um pouquinho com mais um pouquinho melhor, né?

É o dinheiro, né... Que nem eu que fico os 6 meses em casa, tem que guardar uma reservinha para a entressafra, né.

A inserção da mulher no mercado de trabalho contribui para mudanças no sentido econômico, social e psicológico. Quando a mulher passa a ter renda, esta passa a ter voz ativa, tornando-se menos dependente dos outros, especialmente de figuras masculinas. De maneira geral, através do trabalho, as 
mulheres passam a ter um controle maior sobre determinada esferas de suas vidas. Além disso, a contribuição da mulher para o crescimento da família torna-se mais visível socialmente quando passa a trabalhar fora de casa e recebe um salário (Sen, 2000). Contudo, cabe salientar que os salários das mulheres ainda são concebidos - até mesmo pelas próprias trabalhadoras safristas - como um complemento, uma "ajuda" a renda dos cônjuges.

Para complementar a renda, né...

É porque eu precisava, era só eu e meu marido. Ele trabalhando, e nós tínhamos duas crianças já, né. Daí nós como tinha uma casinha velha $e$ nós queria fazer uma casa nova, eu disse: "não vamos lá, eu te ajudo a trabalhar".

[...] Daí eu disse "não, eu vou te ajudar". Porque ele sozinho ele não ia conseguir.

[...] Mas ajudei mesmo a juntar o dinheiro, todo final do mês eu recebia e ele recebia também e ia lá e comprava as coisas. E fumo fazendo nossa casa. Em dois anos estávamos com nossa casa pronta.

A inserção da mulher no mercado de trabalho aconteceu através de profissões que necessitavam baixa qualificação e consequentemente, baixa remuneração. Devido a isso ligou-se a ideia de que seu salário seria complemento aos salários de seus companheiros. Assim, o trabalho da mulher não era visto como realização profissional ou emancipação econômica, mas sim como um complemento financeiro a renda familiar (Machado, 2003). Dessa forma, construiu-se a concepção de que o trabalho do homem é considerado fundamental, sendo este $o$ provedor da família, e o trabalho da mulher como sendo complementar.

[...] e aí fico mais dependente do marido. Mais dependente do marido.
Aí tu não tem como ajudar. Não pode contar com nada, né. Ele não pode contar com nada contigo.

Percebe-se o quanto o fato de não estar trabalhando, torna-as dependentes de seus cônjuges, situação esta, que lhes causa incomodo e desconforto. Assim, um dos fatores que se mostrou preponderante para o ingresso e reingresso na safra do fumo, de acordo com as falas das trabalhadoras safristas, é a questão financeira. Ao trabalharem, passam a conquistar de certo modo o seu espaço dentro da família e da sociedade, bem como adquirir bens que desejam. Contudo, o trabalho ainda é concebido como uma "ajuda" a renda dos companheiros, não sendo visto como importante e principal.

\section{Considerações finais}

O trabalho ocupa um lugar de destaque na vida dos sujeitos tendo um papel potencializador de empoderamento e emancipação, de produção de subjetividade e de reconhecimento social, bem como de vivências de prazer e realização. Entretanto, pode se tornar alienante e causador de sofrimento, na medida que o capital se apropria de certas organizações e relações de trabalho.

A hipótese inicial de que no trabalho da safra do fumo é composto principalmente por mulheres, foi confirmado através das falas das participantes. Este, torna-se uma oportunidade de inserção no mercado de trabalho, visto que, por possuírem baixa escolaridade e/ou baixa qualificação, tiveram dificuldades de ingressar em outros contextos de trabalho. Ademais, tendo em vista o modo de organização deste trabalho sazonal, tornase uma possibilidade de trabalho para muitas mulheres que não possuem alternativas de locais para deixarem seus filhos, tendo em vista que estas ainda são as principais responsáveis pelo cuidado dos mesmos.

Constatou-se que as mulheres desempenham tarefas mais desqualificadas e 
repetitivas dentro do processo de produção, enquanto os homens ficam em cargos de chefia, denotando a exploração da força feminina de trabalho. Além disso, o trabalho de safra foi definido culturalmente como um "trabalho de mulher", devido as características necessárias para o desenvolvimento das tarefas - minuciosidade e delicadeza - que são atribuídas socialmente ao feminino.

$\mathrm{O}$ ingresso no período da safra possibilita que muitas mulheres possam se empoderar tanto financeiramente, quanto socialmente. Mesmo que não aconteça durante o ano todo, no período em que estão trabalhando, conseguem adquirir bens que desejam, possuindo maior liberdade e autonomia de escolha. Além disso, há uma "fuga" da rotina doméstica, em que os companheiros passam a "ajudar" mais nas atividades diárias, não as sobrecarregando nesse período. Assim, o trabalho na safra possibilita que as mulheres desempenhem outras tarefas que não somente as do âmbito doméstico, bem como se torna um espaço de socialização com outras pessoas.

Outra questão que se tornou preponderante durante o processo de escuta destas trabalhadoras, foi que há um grande descontentamento em relação as modificações nas contratações. Atualmente, a Lei do Contrato Temporário 13.429 (Brasil, 2017) permite que o(a) trabalhador(a) trabalhe durante o prazo de até 180 dias (que pode ser prorrogável até 90 dias ou não). Há uma insatisfação em relação a estas modificações, visto que anteriormente o período de contratação nas safras eram mais longos, chegando a permanecerem neste trabalho temporário durante o período de 11 meses. Contudo, as participantes parecem não se dar conta do quanto este trabalho é precarizado e do quanto teriam mais benefícios e direitos garantidos, caso fosse um trabalho efetivo.

A lógica deste trabalho sazonal atravessa a produção subjetividade destas trabalhadoras. Mesmo com a ruptura previsível durante o processo de trabalho, há uma espera para a próxima safra. Algumas participantes, inclusive, quando tiveram a oportunidade de um emprego fixo, retornaram para a safra, apontando este como um "vício". Essas questões denotam, portanto, a maneira como as trabalhadoras se estruturam e se organizam neste contexto de trabalho, se subjetivando nesta temporalidade sazonal, seja pela falta de opções emprego ou pela repetição durante vários anos na safra, mesmo que contrarie o desejo de um emprego que efetivo.

\section{Referências}

Antunes, R. (2009). Os sentidos do trabalho: ensaio sobre a afirmação e a negação do trabalho. São Paulo: Boitempo.

Bouyer, G. C. (2010). Contribuição da Psicodinâmica do Trabalho para o debate: "o mundo contemporâneo do trabalho e a saúde mental do trabalhador". Revista Brasileira de Saúde Ocupacional, 35(122), 249-259. doi: 10.1590/S030376572010000200007.

Brasil. Lei $n^{\circ} 13.429$, de 31 de março de 2017. Recuperado em 13 de maio de 2017, em http://www.planalto.gov.br/ccivil_03/_Ato 2015-2018/2017/Lei/L13429.htm\#art1.

Cadoná, M. A. (2015). A indústria fumageira e o mercado de trabalho de Santa Cruz do Sul-RS. Revista brasileira de desenvolvimento regional, 3 (1), 205-221. doi: $10.7867 / 2317-5443.2015 \mathrm{v} 3 \mathrm{n} 1 \mathrm{p} 205-$ 221.

Castel, R. (2003). As metamorfoses da questão social: uma crônica do salário. Petrópolis: Vozes.

Cortez, M. B., \& Souza, L. (2008). Mulheres (in) subordinadas: o empoderamento feminino e suas repercussões nas ocorrências de violência conjugal. Psicologia: Teoria e Pesquisa, 24(2), 171180. doi: $\underline{10.1590 / S 0102-}$ 37722008000200006.

Coutinho, M. C., Krawulski, E., \& Soares, D. H. P. (2007). Identidade e trabalho na conteporaneidade: repensando articulações possíveis. Psicologia \& Sociedade, 19(spe), 
29-37. doi: $10.1590 / \mathrm{S} 0102-$

71822007000400006.

D’Alonso, G. L. (2008). Trabalhadoras brasileiras e a relação com o trabalho: trajetórias e travessias. Psicologia para América Latina (15). Recuperado de http://pepsic.bvsalud.org/scielo.php?script= sci_abstract\&pid=S1870-

350X2008000400003\&lng=esem.

Dejours, C. (1992). A Loucura do Trabalho:

Estudo de Psicopatologia do Trabalho. São Paulo: Cortez.

Dejours, C. (2008). In S, Lancman, L, Sznelwar (Orgs.), Christophe Dejours: da psicopatologia à psicodinâmica do trabalho. Rio de Janeiro: Ed. Fiocruz.

DIEESE (Departamento Intersindical de Estatística e Estudos Socioeconômicos), (2017). Os impactos da Lei 13.429/2017 (antigo PL 4.302/1998) para os trabalhadores. Nota Técnica, $\mathrm{n}^{\circ} 175$. Recuperado em 20 de maio de 2017, em https://www.dieese.org.br/notatecnica/2017 InotaTec175TerceirizacaoTrabalhoTempor ario/?page $=1$.

Fiorin, P. C., Oliveira, C. T., \& Dias, A. C. G. (2014). Percepções de mulheres sobre a relação entre trabalho e maternidade.

Revista Brasileira de Orientação

Profissional, 15(1), 25-35. Recuperado de http://pepsic.bvsalud.org/scielo.php?script $=$ sci_arttext\&pid=S1679$33902014000100005 \& \operatorname{lng}=$ pt\&tlng=pt.

Flach, L., Grisci, C. L. I., Silva, F. M., \& Manfredini, V. (2009). Sofrimento psíquico no trabalho contemporâneo: analisando uma revista de negócios. Psicologia \& Sociedade, 21(2), p. 193-202. doi: 10.1590/S0102-71822009000200006.

Goulart Junior, E., Mergulhão, L. R., Canêo, L. C., Najm, M. B., \& Lunardelli, M. C. F. (2009). Considerações sobre a terceira idade e o mercado de trabalho: questionamentos e possibilidades. Revista Brasileira de Ciências do Envelhecimento Humano, 6(3), 429-437. doi: 10.5335/rbceh.2012.250.

Grisci, C. L. I. (1999). Trabalho, tempo e subjetividade: impactos da reestruturação produtiva e o papel da Psicologia nas organizações. Psicologia: Ciência e Profissão, 19(1), 2-13. doi: 10.1590/S141498931999000100002.

Guiraldelli, R. (2014). Trabalho, trabalhadores e questão social na sociabilidade capitalista. Cadernos de Psicologia Social do Trabalho, 17(1), 101-115. Recuperado d http://pepsic.bvsalud.org/scielo.php?script= sci_arttext\&pid=S151637172014000200008.

Hirata, H. (2002). Nova divisão sexual do trabalho? Um olhar voltado para a empresa e a sociedade. São Paulo: Boitempo.

Macedo, F. M. F., Boava, D. L. T., Cappelle, M. C. A., \& Oliveira, M. L. S. (2012). Relações de gênero e subjetividade na mineração: um estudo a partir da fenomenologia social. Revista de Administração Contemporânea, 16(2), 217236. doi: $10.1590 / \mathrm{S} 1415-$ 65552012000200004.

Macêdo, G. S., \& Macedo, K. B. (2004). As relações de gênero no contexto organizacional: o discurso de homens e mulheres. Revista Psicologia:

Organizações e Trabalho, 4(1), 61-90. Recuperado de https://periodicos.ufsc.br/index.php/rpot/art icle/view/7548.

Machado, O. M. (2003). Códigos legais e códigos sociais - o papel dos direitos e os direitos de papel. In M. A. I. Hesketh (Org.). Cidadania da mulher, uma questão de justiça. Brasília: OAB Editora.

Nascimento, S. D. (2014). Precarização do trabalho feminino: a realidade das mulheres no mundo do trabalho. In III Simpósio Gênero e Políticas Públicas (paginação irregular). Londrina, PR.

Nogueira, C. M. (2004). A feminização no mundo do trabalho: entre a emancipação e a precarização. Campinas: Autores Associados.

Queiroz, V. S, Aragón, J. A. O. (2015). Alocação de tempo em trabalho pelas mulheres brasileiras. Estudos Econômico, 45(4), 787-819. doi: 10.1590/0101416145484vqj. 
Sen, A. (2000). Desenvolvimento como

Liberdade. São Paulo: Companhia das

Letras.

Tavares, L. A. T. (2010). A depressão como "mal-estar" contemporâneo: medicalização e (ex)-sistência do sujeito depressivo. São Paulo: Editora UNESP.

Redin, E. (2015). Família rural e produção do tabaco: estratégias de reprodução social em Arroio do Tigre/RS (Tese de doutorado). Programa de Pós-graduação em Extensão
Rural e Desenvolvimento da Universidade de Santa Maria (UFSM), Rio Grande do Sul.

Thiollent, M. (1988). Metodologia da pesquisa-ação. São Paulo: Cortez.

Vanalli, A. C. G., \& Barham, E. J. (2012). Após a licença maternidade: a percepção de professoras sobre a divisão das demandas familiares. Psicologia \& Sociedade, 24(1), 130-138. doi: 10.1590/S0102$\underline{71822012000100015 .}$.

\section{Dados sobre as autoras:}

- Renata da Silveira Borstmann: Mestranda em Psicologia Social e Institucional pela Universidade Federal do Rio Grande do Sul - UFRGS. Graduada em Psicologia pela Universidade de Santa Cruz do Sul - UNISC. Integrante do grupo N-PISTA(s) - Núcleo de Pesquisas Instituições, Subjetivação e Trabalho em Análise(s) - PPGPSI/UFRGS.

- Karine Vanessa Perez: Doutora e Mestre em Psicologia Social e Institucional pela UFRGS. Docente da Universidade de Santa Cruz do Sul. Psicóloga, graduada em Psicologia com Especialização em Psicologia Clínica Humanista pela Universidade do Oeste de Santa Catarina - Campus de São Miguel do Oeste. Integrante do Laboratório de Psicodinâmica do Trabalho PPGPSI/UFRGS. Experiência na área de Psicologia, ênfase em Psicologia Social e Saúde Mental e Trabalho. 